Original Research Paper

\title{
New Strategy to Optimize Lean Supply Chain Design by Meta-Heuristic
}

\author{
Thi Hong Dang Nguyen and Thien My Dao \\ Department of Mechanical/Manufacturing Engineering, \\ École de Technologie Supérieure, Montréal, Québec, Canada
}

\author{
Article history \\ Received: 20-02-2017 \\ Revised: 02-03-2017 \\ Accepted: 08-03-2017 \\ Corresponding Author: \\ Thi Hong Dang Nguyen \\ Department of Mechanical/ \\ Manufacturing Engineering, \\ École de Technologie \\ Supérieure, \\ Montréal, Québec, Canada \\ Email: thi-hong- \\ dang.nguyen.1@ens.etsmtl.ca
}

\begin{abstract}
This paper aims at presenting one novel quantitative strategy of optimizing the design of Lean supply chain using Meta-Heuristics. While classifying Lean Manufacturing tools in two categories, namely Functional and Tier Lean tools, we propose a new framework to design the Lean supply chain by implementing the former into a 5-echelon Fat supply chain. As the following step, we investigate the effect of the latter on the mentioned Lean supply chain model. Then, we utilize the tight correlation of Tier Lean tools and priority-based Genetic Algorithm Meta-Heuristics in order to optimize the configuration of the Lean supply chain. Finally, these ideas are illustrated step by step in one numeral example.
\end{abstract}

Keywords: Lean Supply Chain Design, Functional Lean Tools, Tier Lean Tools, Priority-Based Genetic Algorithm, Optimization

\section{Introduction}

Supply Chain Management (SCM) is a respected area today, as future competition in the field of business will be based on Supply Chains (SC) system rather than individual enterprises (Rice and Hoppe, 2001). Several models of SC have been studied as part of the incessant efforts taken to improve the competitive advantages of enterprises. Among them, the Lean Supply Chain (LSC) is assessed as an "ideal SC" (Srinivasan, 2012) since it can promptly and economically deliver the final products/services to customers in a seamless manner. The objective of the LSC is to eliminate non-value added activities as well as reduce the required non-value added activities (Anand and Kodali, 2008). Deborah (2005) analyses and compares the characteristics of the Fat Supply Chain (FSC) and LSC, thereby asserting the undeniable benefits and power of the LSC over the FSC.

In the SCM domain, the Supply Chain Design (SCD) directly impacts the performance of the SC since it creates a proper platform for all activities in the chain. Harrison (2001) suggests that approximately $80 \%$ of the total product cost may be fixed with SCD decisions. Nonetheless, the design space of the SCD contains a vast number of alternatives (Leukel and Sugumaran, 2013), which makes it hard to define the best solutions. Over time, the developments of information technology and optimization techniques make this difficulty solvable through optimization, simulation, or heuristics (Harrison, 2001). Recently, numerous Meta-Heuristics (MH) which are improved from heuristics, have proven effective in resolving SCD issues.

Inspired by such attractions, we introduce in this study a new quantitative strategy to design LSC by MH. The forthcoming sections in this study are organized into as followings: Literature review; new strategic framework of the Lean Supply Chain Design (LSCD), including the FSC formation, LSC transformation and its optimization by priority-based Genetic Algorithm (pGA); a numerical example; and conclusion.

\section{Literature Review}

SCD is a rich domain of SCM. Farahani et al. (2015) classifies SCD into five main rubrics: (1) Network structure; (2) Non-strategic decision of the SC; (3) Technology type/production philosophy; Environmental condition of the model; and (5) Objective of mode, which includes LSC and other kinds of SC. Ugochukwu et al. (2012) states, "When Lean is implemented across the entire $S C$, the $S C$ is referred as a LSC." Findings from the exhaustive review of Anand and Kodali (2008) show that previous studies concentrated on transforming the current FSC into LSC, rather than building a brand new LSC in its design stage. 
This study enumerates up to $59 \mathrm{LM}$ tools/techniques available for LSC transformation. They are classified into four categories: (1) IT-based; (2) SCM-based; (3) Organization-based; and (4) JIT or LM elements.

Theoretically, the SCD process has been described through various models, in which the 5-stage SC Outline Process (SCOP) proposed by Corominas et al. (2015) profoundly draws out an SCD roadmap. To begin with, the first stage focuses on identifying the environment and objectives of the new SC. Further, stage 2 defines the SC macrostructure. Then, stage 3 identifies the SC mesostructure. Stage 4 specifies the SC microstructure, in which all SC specifications (objectives, parameters, constraints and variables) are formulated into mathematical models. Final stage chooses the optimal SC configuration among obtained results. There are two main solution methodologies in this stage: Exact solution and heuristics or $\mathrm{MH}$ (Melo et al., 2008). Tiwari et al. (2010) realize the growing tendency of using $\mathrm{MH}$ as they can offer acceptably good solutions with relatively little CPU time. Especially, the application of $\mathrm{MH}$ in SCM and SCD is well reviewed by Stanley et al. (2012). The study finds that GA, a globally optimal MH inspired by evolutionary biology (Holland, 1962), is the most prevalent. During the time, GA is modified and hybridised with various algorithms in order to improve its search quality (Jaramillo et al., 2002). Among of which, pGA, proves useful in designing the SC (Mitsuo et al. 2006). It is noteworthy that pGA is superior to Spanning Tree-based GA by using a simpler decoding procedure to generate random feasible chromosomes.

\section{New Strategic Framework of LSCD}

The new strategic framework of the LSCD includes three main stages and eight sub-steps (Fig. 1). To elaborate, suitable LM tools selected among 59 items in review of Anand and Kodali (2008) are implemented into the fourth and fifth stage of the SCOP model (Corominas et al., 2015). These tools are classified into two categories that play a distinct role in the LSCD process: Functional Lean tools (which influence the SC total cost with daily operating functions) and Tier Lean tools (which affect the SC configuration), as depicted in Fig. 2. The entire process is particularly explained in turn below.

\section{Formulate the FSC Model}

The objective function of the FSC is to minimize the SC performance - Total Cost (TC), which is apportioned from SC tiers and functions as modified in study of Shretta et al. (2015), (Fig. 3a). The former include the Supplier (S), Plant (P), Distribution Centre (DC), Warehouse (WH) and Customer (C). The latter comprises five basic functions: Procurement, Production, Delivery, Inventory and Quality Assurance, which are described by the SC TC tree (Fig. 3b). Thus, the general FSC TC can be formulated from the five mentioned elements together with the Facility Installation cost. It is noted that all costs that are derived from suppliers are cumulated with the Material cost. Specifically, FSC TC is formulated in Equation 1 as follows:

FSC TC $=$ Total Cost $[$ Procurement + Production $]$
+ Inventory + Delivery + Quality + Installation

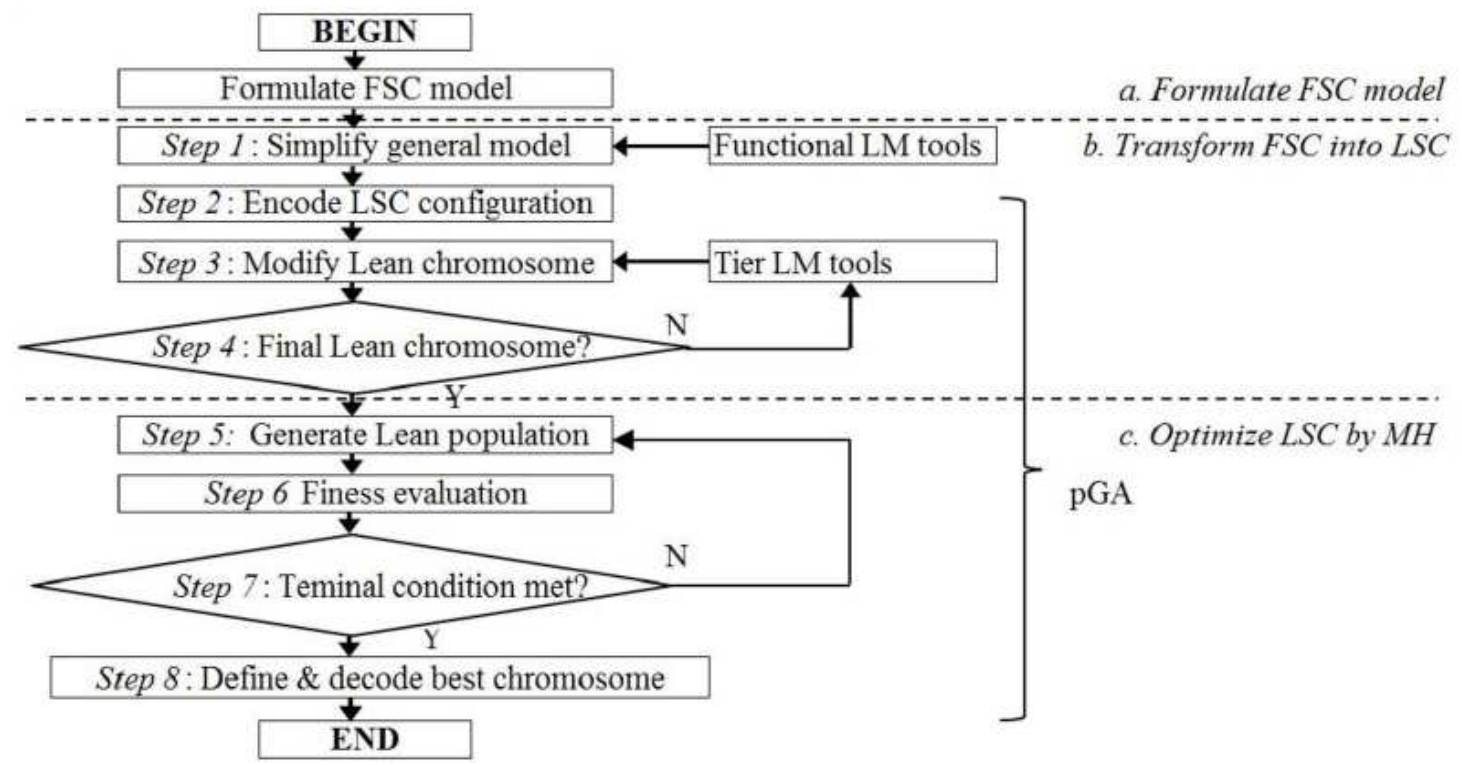

Fig. 1. Framework for optimizing the LSCD by the pGA 


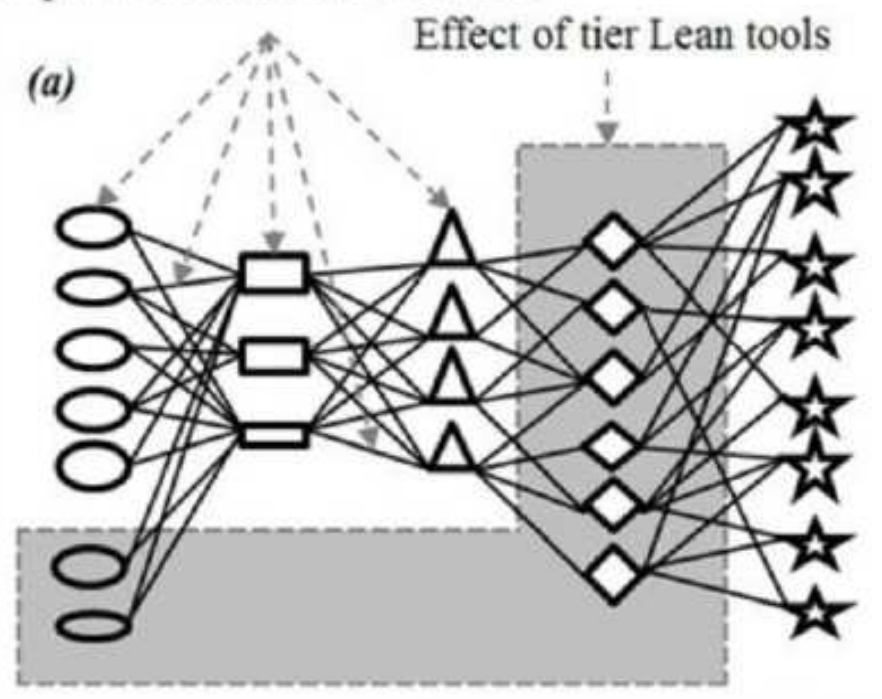

\section{Supplier Plant DC WH Customer}

Fig. 2. Impact of Functional Lean tools and Tier Lean tools on the SC

\begin{tabular}{|c|c|c|c|c|c|c|}
\hline \multirow{3}{*}{ SC Function } & \multicolumn{5}{|c|}{ SC Tier } & \multirow{8}{*}{$\begin{array}{l}\text { Total } \\
\text { cost } \\
\text { incurred } \\
\text { by } \\
\text { function }\end{array}$} \\
\hline & Supplier & Plant & DC & Wareh. & Customer & \\
\hline & (S) & (P) & (D) & (W) & (C) & \\
\hline \multicolumn{6}{|l|}{ Procurement } & \\
\hline \multicolumn{6}{|l|}{ Production } & \\
\hline \multicolumn{6}{|l|}{ Inventory } & \\
\hline \multicolumn{6}{|l|}{ Delivery } & \\
\hline \multicolumn{6}{|l|}{ Quality Assurance } & \\
\hline & & & & & & C TC \\
\hline
\end{tabular}

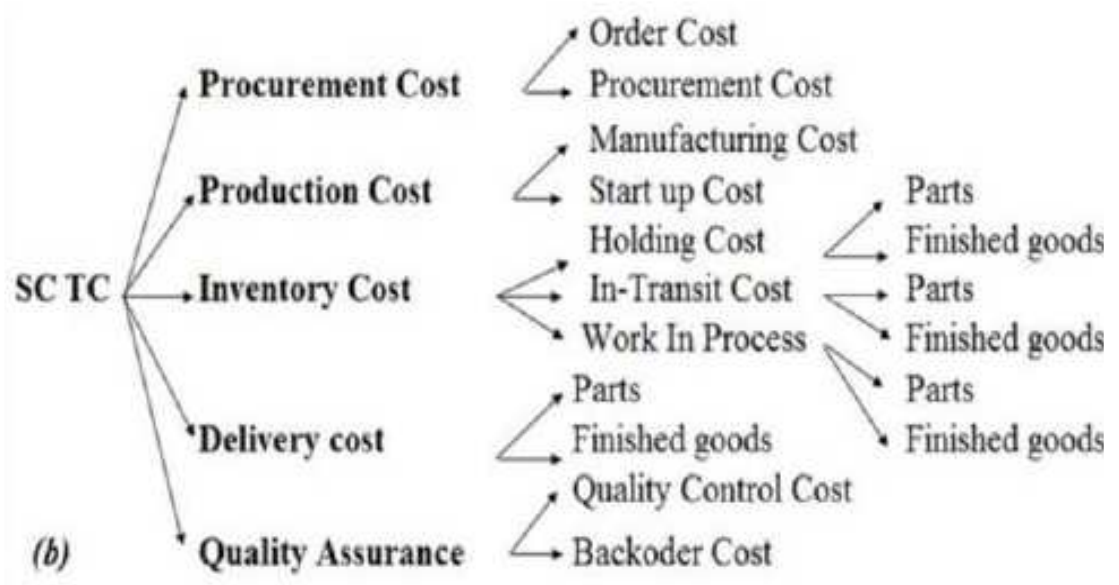

Fig. 3a. FSC TC by tier and function; 3b: SC TC tree 
Thi Hong Dang Nguyen and Thien My Dao / American Journal of Engineering and Applied Sciences 2017, 10 (1): 156.164 DOI: 10.3844/ajeassp.2017.156.164

\begin{tabular}{|c|c|c|c|c|c|c|c|c|}
\hline Element & Sub-Cost 1 & Sub-Cost 2 & $\downarrow s$ & $\mathbf{P}$ & $\downarrow \mathbf{D}$ & $\downarrow \mathbf{w}$ & $\mathbf{C}$ & LM Tools affect SCTC through functions \\
\hline \multirow[t]{2}{*}{ Procurement } & Material & & & $\checkmark$ & & & & Developing loyal suppliers, Supplier training \& development \\
\hline & Order & & & $\checkmark$ & $\checkmark$ & & & Information Technology-Supported System \\
\hline \multirow{2}{*}{ Production } & Start Up & & $\checkmark$ & $\checkmark$ & & & & Set up Reduction \\
\hline & Manufacturing & & $\checkmark$ & $\checkmark$ & $\checkmark$ & $\checkmark$ & & JIT/LM; SCM; Organisational elements \\
\hline \multirow{6}{*}{ Inventory } & \multirow{2}{*}{ Holding cost } & Part & $\checkmark$ & $\checkmark$ & & & & \multirow{2}{*}{ JT, Crock-Docking, Milk-run delivery, POUS, Pull System } \\
\hline & & Finished goods & & $\checkmark$ & $\checkmark$ & $\checkmark$ & & \\
\hline & \multirow{2}{*}{ In-Transit } & Part & - & & & & & \multirow{2}{*}{ Crock-Docking, Milk-run delivery, Proximity location } \\
\hline & & Finished goods & & - & & $\Rightarrow$ & $\rightarrow$ & \\
\hline & \multirow{2}{*}{$\begin{array}{l}\text { Work-In- } \\
\text { Process }\end{array}$} & Part & $\checkmark$ & & & & & \multirow{2}{*}{ JT/LM elements } \\
\hline & & Finished goods & & $\checkmark$ & & & & \\
\hline \multirow{2}{*}{ Delivery } & Part & & - & & & & & \multirow{2}{*}{ Crock-Docking, Milk-run delivery, Proximity location } \\
\hline & Finished goods & & & & & - & $\rightarrow$ & \\
\hline \multirow{2}{*}{$\begin{array}{l}\text { Quality } \\
\text { Assurance }\end{array}$} & Quality Control & & $\checkmark$ & $\checkmark$ & $\checkmark$ & $\checkmark$ & & POUS (Point Of Use System), Built-in quality system \\
\hline & Shortage Cost & & $\checkmark$ & $\checkmark$ & $\checkmark$ & $\checkmark$ & & JIT, Continuous Improvement, Point Of Sale (POS) \\
\hline \multicolumn{3}{|c|}{ 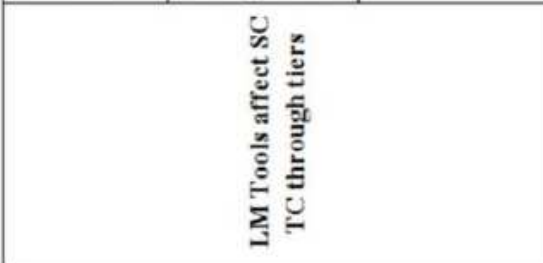 } & 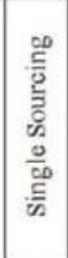 & & \multicolumn{2}{|c|}{ 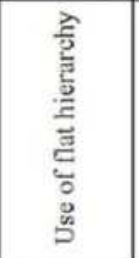 } & & $\begin{array}{l}\text { Where: } \\
\text { Cost being incurred by tier } \\
\text { Ceduce number of suppliers/tiers } \\
\text { Cost can be totally/hugely eliminated } \\
\text { Cost can be gradually reduced }\end{array}$ \\
\hline
\end{tabular}

Fig. 4. Framework of the LSC transformation

By substituting the SC TC structure in Fig. 3a and 3b into Equation 1, the FSC TC yields the following:

FSC TC

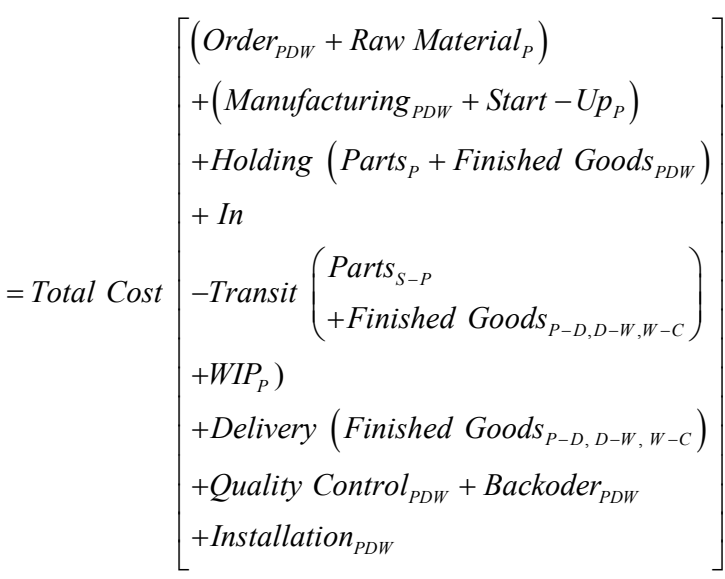

\section{LSC Transformation}

Step 1: Simplify the General Model with Functional Lean Tools (Fig. 4)

After a period of time, if these tools are strictly implemented, they can reduce various SC costs to some extent (completely, remarkably, or gradually). For example, Order cost, Setup cost and Holding/work-in-process cost can be almost eliminated by the IT support system, Setup Reduction and JIT-based element respectively. Similarly, the Intransit and Quality Assurance costs are hugely cut down by the Proximity Location and Built-in Quality System/Point of Sale. Thus, these costs are almost removed out of the TC model in the long run. As a result, Equation 2 remains with only four components: Raw Material, Manufacturing, Delivery and Installation cost. Therefore, the TC of the LSC is simplified from Equation 2 as follows:

LSC TC

$$
=\text { Total Cost }\left[\begin{array}{l}
\text { Raw Material }_{P}+\text { Manufacturing }_{P D W} \\
+ \text { Delivery }_{\left(\text {Finished }_{\text {Good }}\right.} \\
+ \text { Installation }_{P D W}
\end{array}\right]
$$

At the operational level, the objective function Equation 3 can be expressed by mix integer programing as:

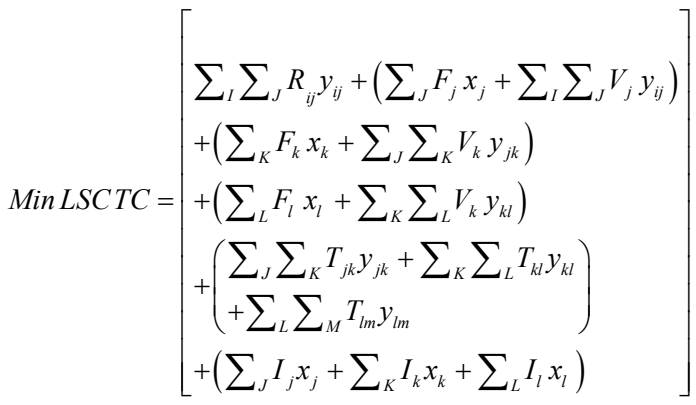


Where:

$R_{i j}$ :

$F_{j}, F_{k}, F_{l}$ :

Unit Material cost of plant $j$ with supplier $i$

$V_{j}, V_{k}, V_{l}$ :

Annual fixed Operating cost of plant $j$, DC $k$, warehouse $l$

Unit variable Operating cost of plant $j$ and unit Throughput cost of DC $k$, warehouse $l$

$T_{j k}, T_{k l}, T_{l m}: \quad$ Unit Transportation cost among adjacent tiers

$I_{j}, I_{k}, I_{l}$ : Installation cost of plant $j$, DC $k$ and warehouse $l$

$C_{j}, C_{k}, C_{l}$ : Capacity of plant $j$ and DC $k$ and warehouse $l$

$D_{j}, D_{k}, D_{l}, D_{m}$ : Demands from plant $j$, DC $k$, warehouse $l$ and customer $l$

\section{Variables}

$x_{j}, x_{k}, x_{l}$ : $\quad$ Binary variable denotes plant $j$, DC $k$, warehouse $l$ opened (1) or closed (0)

$y_{i j}, y_{j k}, y_{k l}, y_{l m}$ : Quantity of material/product shipped among adjacent tiers

\section{Subject to:}

- Balance between quantities received and amount supplies at each node:

$$
\begin{aligned}
& \sum_{I} y_{i j}=\sum_{K} y_{j k} ; \sum_{J} y_{j k}=\sum_{L} y_{k l} \\
& \sum_{K} y_{k l}=\sum_{M} y_{l m}
\end{aligned}
$$

- Satisfy demand from plant, DC, warehouse and customers:

$$
\sum_{I} y_{i j}=D_{j} ; \sum_{J} y_{j k}=D_{k} ; \sum_{K} y_{k l}=D_{m}
$$

- The quantity delivered from each node is less/equal to its capacity:

$$
\sum_{K} y_{j k} \leq C_{j} ; \sum_{L} y_{l k} \leq C_{k} ; \sum_{M} y_{l m} \leq C_{l}
$$

- Non-negative conditions:

$$
y_{i j}, y_{j k}, y_{k l} \geq 0
$$

\section{Step 2: Encode the LSC Configuration}

After simplified, the LSC is encoded by the pGA procedure as in study of Mitsuo et al. (2006) to identify its optimal configuration. The 5-tier SC is encoded through a 7-substring chromosome, in which the first, second and third substrings contain binary variables (open/close plants, DC and WH). The last four adjacent substrings denote transport trees between supplier and plant; plant - DC; DC - WH; then finally, $\mathrm{WH}$ and customer. These strings contain $|\mathrm{I}+\mathrm{J}|,|\mathrm{J}+\mathrm{K}|,|\mathrm{K}+\mathrm{L}|$ and
$|\mathrm{K}+\mathrm{M}|$ digits with random values from 1 to $|\mathrm{I}+\mathrm{J}|,|\mathrm{J}+\mathrm{K}|$, $|\mathrm{K}+\mathrm{L}|$ and $|\mathrm{K}+\mathrm{M}|$ respectively (Fig. 5a).

\section{Step 3: Modify the Lean Chromosome}

When Tier Lean tools are applied, they impact the amount of node/tier in the SC, which changes its denoted chromosome. Particularly, the application of Single Sourcing reduces the number of suppliers to one for each component type. Hence, the supplier-plants transport substring is removed because its configuration becomes deterministic (Fig. 5b). Similarly, the Use of Flat Hierarchy can minify the intermediary tiers in the supplier-plant or/and plant-customer substrings. Thus, the correlative substrings of these tiers are deleted. Figure 5c represents the chromosome of the LSC when Single Sourcing is used and the warehouse stage is flatted. LSC objective in Equation 4 becomes:

$$
\operatorname{Min} L S C T C=\left[\begin{array}{l}
\sum_{I} \sum_{J} R_{i j} y_{i j}+\left(\sum_{J} F_{j} x_{j}+\sum_{I} \sum_{J} V_{j} y_{i j}\right) \\
+\left(\sum_{K} F_{k} x_{k}+\sum_{J} \sum_{k} V_{k} y_{j k}\right) \\
+\left(\sum_{J} \sum_{K} T_{j k} y_{j k}+\sum_{K} \sum_{M} T_{k m} y_{k m}\right) \\
+\left(\sum_{J} I_{j} x_{j}+\sum_{K} I_{k} x_{k}\right)
\end{array}\right]
$$

\section{Step 4: Final Lean Chromosome?}

The quantity of Tier Lean tools applied depends on the deliberate goals of SC designers. Thereby, the denoted chromosome is correspondingly leaned until the design requirements are met. For instance, other techniques such as Group Technology, Use of Common Part and Modularity are able to change product structure by decreasing the types of components purchased from subcontractors. So, they reduce number of suppliers and genes on chromosomes simultaneously.

\section{Optimise LSC by $p G A$}

\section{Step 5: Generate Lean Population Pool}

Heuristically, pGA uses the same procedure as GA to randomly generate and handle the offspring in a population pool.

\section{Step 6: Fitness Evaluation}

After created, each offspring is decoded to the transportation tree in order to calculate the fitness (LSC TC). In pGA, each gene on a chromosome has two factors: Locus and allele. Locus is the position of genes denoting the order of source/destination in the transportation tree. Meanwhile, the gene value of allele bears represents the priority level of nodes assigned to the transportation tree. The decoded procedure determines the highest allele on a chromosome. Its corresponding locus is referred to the node having the priority to be served or delivered. 


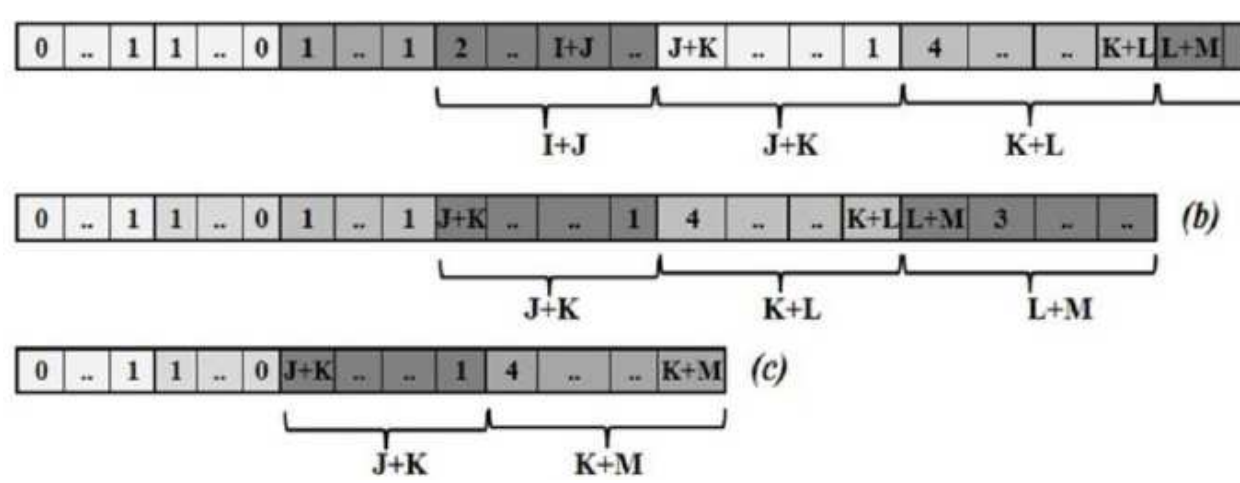

Fig. 5a. General LSC chromosome; (b) LSC chromosome while using Single Sourcing; (c) LSC chromosome while applying Single Sourcing and the Use of Flat Hierarchy

Then, the shipment from this node with its counterpart is established, provided that the transportation cost between them in the cost matrix is the lowest. When any node is completely supplied/ served, its correlative allele is assigned to zero. The assignment repeats until all alleles on the chromosome adopt the null value. At that time, the transportation tree is totally built and the fitness is computed based on this network.

\section{Step 7: Terminated Condition Met?}

The terminated condition can be set similar to the GA.

\section{Step 8: Define and Decode the Best Chromosome}

Finally, the chromosome contributing to the best fitness is defined and then decoded in order to identify the best configuration of the LSC.

\section{Illustrative Example}

To illustrate the aforementioned method, one numerical example of the LSC design is described step by step. Assuming that all information in Step 1, 2 and 3 of the SCOP model is defined, the designers outline one potential FSC structure including 7 suppliers, 4 plants, 5 DCs and 8 WHs to serve 8 customers, in which supplier 1 and 2 provide the same components as supplier 6 and 7. While examining three assumptions and collected data in Table 1 and 2, the managers want to lean both the supply side and the demand side, with only 5 suppliers, 3 plants, 4 DCs, 6 WHs selected. Assumptions:

- Suppliers' capacities satisfy demands of all plants

- Customers' demands are deterministic and must be satisfied completely

- All the transportation links between adjacent tiers are available

\section{Step 1: Simplify the General Model}

Designers intend to implement Functional Lean tools in Fig. 3 into their draft of the FSC. When transformed, the LSC TC contains four factors like Equation 3.

\section{Step 2: Encode the LSC Configuration}

With $\mathrm{I}=5, \mathrm{~J}=3, \mathrm{~K}=4, \mathrm{~L}=6$ and $\mathrm{M}=8$, the chromosome of the LSC structure is randomly denoted with 7 substrings, 56 digits (Fig. 6).

\section{Step 3: Modify the Lean Chromosome}

When Single Sourcing is applied, supplier 6 and 7 are dropped (their material cost higher than competitors'), so their supplies are transferred to supplier 1 and 2 (the forth substring is removed). Since the supply side is leaned, The Use of Flat Hierarchy is then used to clear the warehouse tier (substrings WH and D-W are wiped out). Thus, DCs serve customers directly and the last substring W-C turns out as D-C. The LSC chromosome is then modified as Fig. 7.

\section{Step 4: Final Lean Chromosome?}

In this case, other Tier Lean tools have not been applied. Therefore, the chromosome representing the LSC structure defined in Step 3 is final.

\section{Step 5: Generate Lean Population}

The mutation and crossover rates are set at 0.1 and 0.8 respectively.

\section{Step 6: Fitness Evaluation}

Lean chromosomes are decoded to compute the fitness from Equation 10:

$$
\operatorname{Min} L S C T C=\left[\begin{array}{l}
\sum_{5} \sum_{3} R_{i j} y_{i j}+\left(\sum_{3} F_{j} x_{j}+\sum_{5} \sum_{3} V_{j} y_{i j}\right) \\
+\left(\sum_{4} F_{k} x_{k}+\sum_{4} \sum_{3} V_{k} y_{j k}\right) \\
+\left(\sum_{3} \sum_{4} T_{j k} y_{j k}+\sum_{4} \sum_{8} T_{k m} y_{k m}\right) \\
+\left(\sum_{3} I_{j} x_{j}+\sum_{4} I_{k} x_{k}\right)
\end{array}\right]
$$




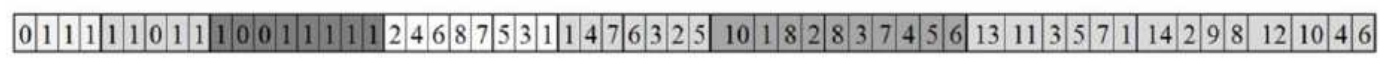

$\underbrace{\prime}_{4(\mathrm{P})} \underbrace{\prime}_{5(\mathrm{D})} \underbrace{\prime}_{8(\mathrm{~W})} \underbrace{\prime}_{8(\mathrm{~S}-\mathrm{P})} \underbrace{\prime}_{7(\mathrm{P}-\mathrm{D})} \underbrace{\prime(\mathrm{W}-\mathrm{C})}_{10(\mathrm{D}-\mathrm{W})}$

Fig. 6. One example chromosome of the LSC while using Functional Lean tools

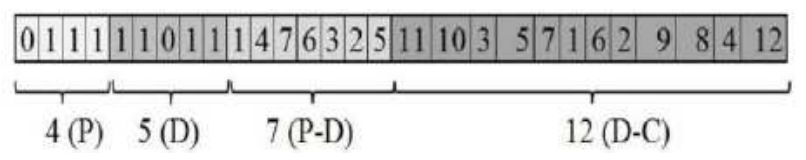

Fig. 7. Random LSC chromosome while using Single Sourcing and The Use of Flat Hierarchy

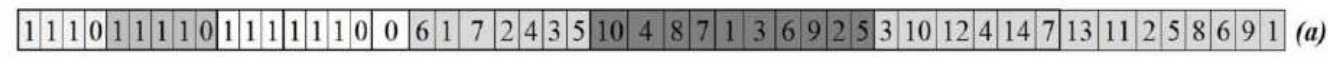

$\underbrace{1}_{4(\mathrm{P})} \underbrace{1}_{6(\mathrm{DC})} \underbrace{1}_{7 \text { (P-D) }}$

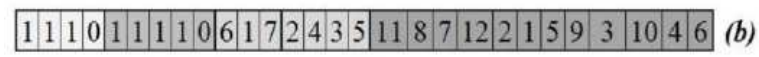

4 (P) 5 (DC) 7 (P-D)

Fig. 8. (a) Best LSC chromosome under the Functional Lean tools effect; (b): Final LSC chromosome
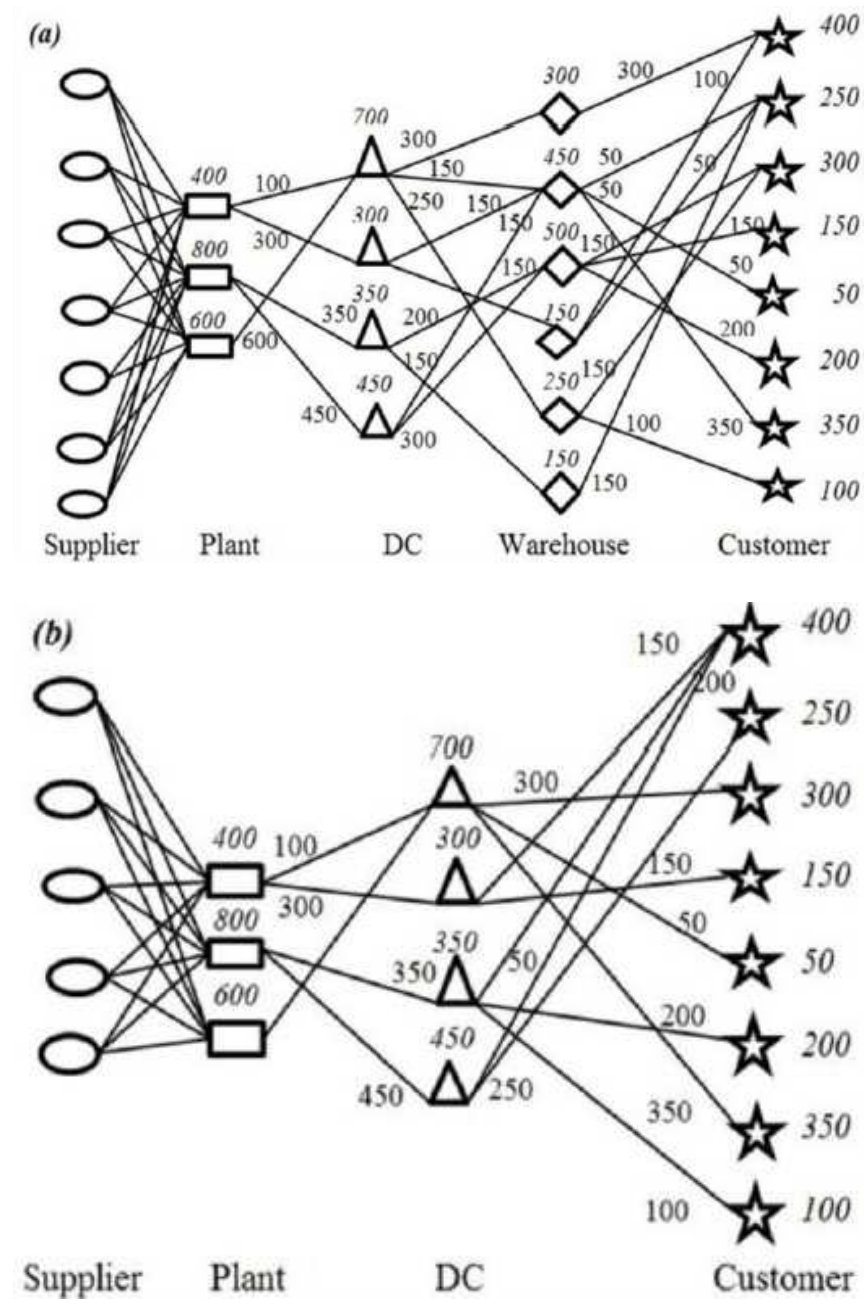

Fig. 9. (a) Best LSC under the Functional Lean tools effect; (b) Final LSC configuration 


\begin{tabular}{|c|c|c|c|c|c|c|c|c|c|c|c|c|c|c|c|c|}
\hline \multirow[b]{2}{*}{ No } & \multicolumn{5}{|c|}{ Plant } & \multicolumn{5}{|l|}{$\mathrm{DC}$} & \multicolumn{5}{|c|}{ Warehouse } & \multirow{2}{*}{$\begin{array}{l}\text { Cus } \\
\text { Dm }\end{array}$} \\
\hline & $\mathrm{Dj}$ & $\mathrm{Cj}$ & $\mathrm{Fj}$ & $\mathrm{Vj}$ & $\mathrm{Ij}$ & $\mathrm{Dk}$ & $\mathrm{Ck}$ & $\mathrm{Fk}$ & $\mathrm{Vk}$ & $\mathrm{Ik}$ & $\mathrm{D} 1$ & $\mathrm{Cl}$ & $\mathrm{F} 1$ & V1 & Il & \\
\hline 1 & 400 & 500 & 50,000 & 25 & 700,000 & 700 & 550 & 13,200 & 8,250 & 245,000 & 300 & 350 & 5,100 & 2,400 & 52,500 & 400 \\
\hline 2 & 800 & 900 & 108,000 & 30 & $1,400,000$ & 300 & 800 & 19,200 & 12,000 & 105,000 & 450 & 500 & 7,650 & 3,600 & 78,750 & 250 \\
\hline 3 & 600 & 750 & 75,000 & 28 & $1,050,000$ & 350 & 500 & 12,000 & 7,500 & 122,500 & 500 & 600 & 8,500 & 4,000 & 87,500 & 300 \\
\hline 4 & 800 & 1,000 & 116,000 & 35 & $1,480,000$ & 450 & 300 & 7,200 & 4,500 & 157,500 & 150 & 200 & 2,550 & 1,200 & 26,250 & 150 \\
\hline 5 & & & & & & 700 & 450 & 10,800 & 6,750 & 315,000 & 250 & 300 & 4,250 & 2,000 & 43,750 & 50 \\
\hline 6 & & & & & & & & & & & 150 & 250 & 2,550 & 1,200 & 26,250 & 200 \\
\hline 7 & & & & & & & & & & & 300 & 350 & 5,100 & 2,400 & 58,500 & 350 \\
\hline 8 & & & & & & & & & & & 150 & 200 & 2,850 & 1,200 & 29,250 & 100 \\
\hline
\end{tabular}

Table 2. SC cost matrix

\begin{tabular}{|c|c|c|c|c|c|c|c|c|c|c|c|c|c|c|c|c|c|c|c|}
\hline & S1 & S2 & S3 & $\mathrm{S} 4$ & S5 & D1 & $\mathrm{D} 2$ & D3 & D4 & D5 & $\mathrm{C} 1$ & $\mathrm{C} 2$ & $\mathrm{C} 3$ & $\mathrm{C} 4$ & $\mathrm{C} 5$ & C6 & $\mathrm{C} 7$ & $\mathrm{C} 8$ & \\
\hline & & & & & & & & & & & 18.5 & 19.6 & 16.7 & 16.8 & 15.3 & 20.1 & 15.4 & 18.9 & D1 \\
\hline P1 & 123.2 & 129.8 & 120.4 & 134.5 & 132.1 & 11.3 & 12.4 & 13.3 & 12.7 & 19.8 & 17.4 & 16.8 & 15.8 & 15.4 & 16.8 & 19.5 & 16.4 & 21.4 & D2 \\
\hline P2 & 146.5 & 150.3 & 139.2 & 146.4 & 148.1 & 16.3 & 13.2 & 14.3 & 12.1 & 18.4 & 16.7 & 18.3 & 19.4 & 15.8 & 18.5 & 17.4 & 15.8 & 20.4 & D3 \\
\hline P3 & 135.7 & 137.5 & 136.4 & 143.6 & 129.5 & 10.5 & 12.7 & 11.1 & 14.7 & 16.3 & 15.6 & 15.2 & 20.1 & 17.7 & 16.4 & 17.2 & 21.3 & 15.7 & D4 \\
\hline \multirow[t]{9}{*}{ P4 } & 155.4 & 168.2 & 163.3 & 170.4 & 161.3 & 11.8 & 14.7 & 14.8 & 15.1 & 15.2 & 18.2 & 24.1 & 23.4 & 17.9 & 18.7 & 20.6 & 22.7 & 24.5 & D5 \\
\hline & & & & & W1 & 5.4 & 6.2 & 7.3 & 9.4 & 11.5 & 4.3 & 5.4 & 6.8 & 6.2 & 5.2 & 5.7 & 4.8 & 4.7 & \\
\hline & & & & & W2 & 7.8 & 6.4 & 5.9 & 8.7 & 10.6 & 5.6 & 5.9 & 4.1 & 5.7 & 4.8 & 6.3 & 5.2 & 7.2 & \\
\hline & & & & & W3 & 10.3 & 9.5 & 10.1 & 6.3 & 10.4 & 6.4 & 6.2 & 5.3 & 4.4 & 5.1 & 4.6 & 6.3 & 4.8 & \\
\hline & & & & & W4 & 8.8 & 5.7 & 6.3 & 5.8 & 9.5 & 4.7 & 6.3 & 5.5 & 6.1 & 4.8 & 5.2 & 4.4 & 7.3 & \\
\hline & & & & & W5 & 6.5 & 8.4 & 9.2 & 7.7 & 10.5 & 6.9 & 6.8 & 4.1 & 5.9 & 6.6 & 4.3 & 5.6 & 4.1 & \\
\hline & & & & & W6 & 8.2 & 5.9 & 8.2 & 7.3 & 8.8 & 5.3 & 4.6 & 6.4 & 5.3 & 4.8 & 5.8 & 6.7 & 5.5 & \\
\hline & & & & & W7 & 7.9 & 8.7 & 9.8 & 9.3 & 11.4 & 4.8 & 5.7 & 6.6 & 4.5 & 5.9 & 6.1 & 5.8 & 4.7 & \\
\hline & & & & & W8 & 8.7 & 9.2 & 10.7 & 10.6 & 11.5 & 4.2 & 6.2 & 5.3 & 4.7 & 6.5 & 4.6 & 6.9 & 5.4 & \\
\hline
\end{tabular}

\section{Step 7: Terminated Condition Met?}

The iteration is set at 1000 .

\section{Step 8: Define and Decode the Best Chromosome}

The best chromosome of the LSC affected by Functional Lean tools in Step 2 is in Fig. 8a, while the optimal one of final LSC is depicted in Fig. 8b. Following this, they are decoded to the best corresponding LSC configurations in Fig. 9a and 9b. The results show that the final structure is much leaner than both FSC and LSC, which are leaned by Functional tools. Concerning fitness, the minimum LSC TC in two situations achieves $\$ 6,198,035$ and $\$ 5,332,175$ in turn. On the other hand, the implementation of both Functional and Tier Lean tools reduce the LSC TC by up to $16.24 \%$ when compared with the cost of the LSC leaned by Functional tools only.

\section{Conclusion}

The paper presents in detail one new quantitative framework to optimise the design of LSC by MetaHeuristics through three main stages: Forming the FSC model; transforming the FSC into LSC; and optimizing the LSCD with pGA. The particular point of this study is that it classifies LM tools into Functional Lean tools and Tier Lean tools. This classification contributes to two important findings:
The framework of the LSC transformation through Functional Lean tools and the integration of Tier Lean tools with pGA to optimise the LSC structure. The solutions from the numerical example prove that this novel approach benefits both the LSC configuration and financial aspects. Moreover, this procedure can clearly draw out a general roadmap for designers, which could assist them in designing their LSC in a quantitative approach. It also offers a reference for the managing cadre in order to flexibly select proper Lean tools that will serve their business objectives.

Along with the selected LM tools in the given instances, other LM techniques related to product design like Modularity, Group Technology and Use of Common Parts also affect the SC structure. Further studies can focus on these areas in order to optimise the conformity of LSC configuration with the product structure.

\section{Funding Information}

The authors have no support or funding to report.

\section{Author's Contributions}

Thi Hong Dang Nguyen: Conduct the research, prepare the manuscripts and do any revisions.

Thien My Dao: Instruct research directions and qualify the solutions; give final approval of the version to be submitted and any revised versions. 


\section{Ethics}

This article is original and contains unpublished material. The corresponding author confirms that all of the other authors have read and approved the manuscript and no ethical issues involved.

\section{References}

Anand, G. and G. Kodali, 2008. A conceptual framework for lean supply chain and its implementation. Int. J. Value Chain Manage., 2: 313-357. DOI: 10.1504/IJVCM.2008.019517

Corominas, A., M. Mateo, I. Ribas and S. Rubio, 2015. Methodological elements of supply chain design. Int. J. Product. Res., 53: 5017-5030. DOI: $10.1080 / 00207543.2015 .1013641$

Deborah, N., 2005. Lean supply chain management principles and practices. Lecture Notes, Integrating the Lean Enterprise.

Farahani, R.Z., S. Rezapour, T. Drezner and S. Fallah, 2015. Supply chain network design classifications paradigms and analyses.

Harrison, T.P., 2001. Global supply chain design. Inform. Syst. Front., 3: 413-416. DOI: $10.1023 / \mathrm{A}: 1012820719986$

Holland, J.H., 1962. Outline for a logical theory of adaptive systems. J. Assoc. Comput. Machinery, 9: 297-314. DOI: $10.1145 / 321127.321128$

Jaramillo, J.H., J. Bhadury and R. Batta, 2002. On the use of genetic algorithms to solve location problems. Comput. Operat. Res., 29: 761-779. DOI: $10.1016 / \mathrm{S} 0305-0548(01) 00021-1$

Leukel, J. and V. Sugumaran, 2013. Formal correctness of supply chain design. Decision Support Syst., 56: 288-299. DOI: 10.1016/j.dss.2013.06.008
Melo, M.T., S. Nickel and D.G.F. Saldanha, 2008. Network Design Decisions in Supply Chain Planning. 1st Edn., Berichte des Fraunhofer ITWM, ISSN-10: 1434-9973, pp: 140.

Mitsuo, G., A. Fulya and L. Lin, 2006. A genetic algorithm for two-stage transportation problem using priority-based encoding. OR Spectrum, 28: 337-354. DOI: 10.1007/s00291-005-0029-9

Rice, J.J.B. and R.M Hoppe, 2001. Supply chain Vs. supply chain: The hype and the reality. Supply Chain Manage. Rev.

Shretta, R., J.M.L. Brittany, D. Seydou, D.D. Don de Savigny and A. Ravi et al., 2015. Costing the supply chain for delivery of ACT and RDTs in the public sector in Benin and Kenya. Malaria J., 14: 57-57. DOI: $10.1186 / \mathrm{s} 12936-014-0530-1$

Srinivasan, M.M., 2012. Building Lean Supply Chains with the Theory of Constraints. 1st Edn., McGraw Hill Professional, New York, ISBN-10: 0071771220, pp: 384.

Stanley, E.G., E.B. John and J.C. David, 2012. Metaheuristics in logistics and supply chain management. J. Bus. Logist., 33: 60-106. DOI: $10.1111 / \mathrm{j} .0000-0000.2012 .01042 . \mathrm{x}$

Tiwari, M.K., N. Raghavendra, A. Shubham and S.K. Goyal, 2010. A hybrid Taguchi-immune approach to optimize an integrated supply chain design problem with multiple shipping. Eur. J. Operat. Res., 203: 95-106. DOI: 10.1016/j.ejor.2009.07.004

Ugochukwu, P., J. Engström and J. Langstrand, 2012. Lean in the supply chain: A literature review. Manage. Product. Eng. Rev., 3: 87-96. DOI: $10.2478 / \mathrm{v} 10270-012-0037-6$ 